\title{
MEMPOSTING INFORMASI PADA WEBSITE SMKN 5 KOTA MATARAM
}

\author{
(Posting Information on SMKN 5 Mataram Website) \\ Belmiro Razak Setiawan ${ }^{[1]}$, I Gede Pasek Suta Wijaya ${ }^{[1]}$, Dedi Ermansyah ${ }^{[2]}$ \\ ${ }^{[1]}$ Informatics Engineering Department, Mataram University \\ Jl. Majapahit 62, Mataram, Lombok NTB, INDONESIA \\ ${ }^{[2]}$ Sekolah Menengah Kejuruan Negeri 5 Mataram \\ Jl. Merdeka Raya Pagesangan, Mataram, Lombok NTB, INDONESIA
}

Email:razak.haha@gmail.com,gpsutawijaya@unram.ac.id,dediermansyah72@gmail.com

\begin{abstract}
Abstrak
Sekolah Menengah Kejuuran Negeri 5 Kota Mataram merupakan sekolah menengah kejuruan negeri dengan jurusan kesenian di Kota Mataram. Websitesite yang dimiliki sekolah tersebut diharapkan memberikan berbagai informasi SMKN 5. Aplikasi website yang digunakan adalah Wordpress. Namun, belum ada informasi yang diposting sehingga masih kosong. Maka dari itu, pada kegiatan pengbadian ini, dilakukan penambahan informasi pada website SMKN 5 kota Mataram menggunakan Wordpress. Hal yang dilakukan dalam memposting di Wordpress adalah memposting tulisan, file, gambar, dan menambah halaman. Kegiatan tersebut telah dilakukan sesuai dengan apa yang diinginkan oleh SMKN 5 kota Mataram.
\end{abstract}

Keywords: SMKN 5 kota Mataram, Website, Blog, Wordpress, Memposting.

\section{Pendahuluan}

Pada era globalisasi ini, perkembangan teknologi informasi kini semakin meningkat dan dapat menjadi sarana untuk berbagai kebutuhan manusia. Perkembangan teknologi informasi membuat manusia semakin mudah untuk mengatasi masalah dan kebutuhannya, salah satunya adalah penyampaian informasi. Dalam penyampaian informasi, penyampaiannya harus mudah dan cepat dalam pembuatan kemudian lengkap dan jelas dalam penyampaian informasi. Maka dari itu, website lah jawaban yang tepat untuk mengatasi masalah tersebut. fitur yang terdapat pada website dapat membuat penyampaian dan penulisan informasi lebih efektif dalam ketepatan dan kejelasan pada informasi yang ingin disampaikan. Sehingga, kini website banyak dan sering digunakan oleh banyak orang baik untuk hal yang formal ataupun hal informal.

Sekolah Menengah Kejuruan Negeri 5 kota Mataram merupakan instansi yang bergerak dibidang pendidikan yang memberikan sarana pendidikan untuk siswa siswi yang berada pada tingkat Sekolah Menengah Kejuruan. Jurusan pada sekolah tersebut adalah kesenian baik kesenian tradisional maupun modern. Banyak informasi yang harus disebarkan mengenai sekolah dan kesenian yang dimiliki sekolah tersebut sehingga dapat membuat orang tertarik pada sekolah SMKN 5. Pada sekolah tersebut sudah memiliki website yang berisi tentang SMKN 5 kota Mataram itu sendiri. Namun, permasalahannya adalah belum adanya informasi yang diposting pada website tersebut.

Dari permasalahan tersebut, maka perlu dilakukan penambahan informasi website SMKN 5 Mataram dimana website tersebut dikembangkan dengan menggunakan Wordpress. Wordpress merupakan aplikasi open source untuk membuat website. Wordpress sering digunakan oleh banyak orang dalam membuat website mereka. Wordpress menjadi populer karena mudah dibuat dan dikembangkan serta merupakan aplikasi open source. Sehingga dapat dengan mudah memposting informasi ke website yang dibuat.

\section{Tinjauan Pustaka}

World Wide Website atau WWW atau juga dikenal dengan Website adalah salah satu layanan yang didapat oleh pemakai komputer yang terhubung ke internet. Websitesite atau situs dapat diartikan sebagai kumpulan halaman-halaman yang digunakan untuk menampilkan informasi teks, gambar diam atau gerak, animasi, suara, dan atau gabungan dari semuanya itu baik yang bersifat statis maupun dinamis yang membentuk satu rangkaian 
bangunan yang saling terkait dimana masing-masing dihubungkan dengan jaringan-jaringan halaman (hyperlink)[9]. Fungsi utama pada website antara lain komunikasi, informasi, hiburan, dan transaksi[1].

Websitesite ditinjau dari segi dinamisnya dapat dibagi menjadi dua, yaitu websitesite statis dan dinamis[1]. Halaman website statis adalah halaman website di mana file halaman website yang disimpan di server sama seperti yang terlihat di browser. Sebuah halaman website statis dibuat menggunakan bahasa HTML dan XHTML serta bisa dipercantik dengan CSS dan diberi interaktivitas dengan JavaScript[1]. Sementara halaman websitesite dinamis adalah halaman website di mana tampilan yang dilihat oleh user tidak sama dengan file website di server. Untuk menghasilkan tampilan yang dinamis, sebuah websitesite biasa dibuat menggunakan bahasa pemrograman website, seperti Java Server Pages (JSP), PHP, ASP, dan Perl programming languages, selain itu ada juga YUMA dan ColdFusion (CFM) [10]. Website juga dapat dibedakan jenisnya berdasarkan tujuan. Tujuan website antara lain [1]:

a. Alat pemasaran, Saat ini media pemasaran tidak hanya media cetak saja. Media elektronik sejenis situs juga dapat digunakan sebagai media pemasaran. Pemasaran melalui internet lebih cepat sampai da memiliki jangkauan yang jauh lebih luas.

b. Nilai tambah, Sebuah halaman website merupakan sarana promosi karena media promosi di website lebih murah dan efektif dibandingkan media promosi konvensional seperti brosur, majalah atau Koran. Pada umumnya konten situs website berupa referensi atau informasi tambahan dari apa yang sudah diberikan secara offline. Contohnya seperti di perpustakaan sudah disediakan koleksi skripsi secara tercetak namun di website perpustakaan terdapat repositori skripsi yang lebih banyak dan dapat diakses dengan mudah dengan cara mengunduh bentuk softile nya.

c. Katalog, Untuk di perpustakaan katalognya berupa katalog online yang dapat diakses melalui website perpustakaan. Pada katalog tersebut tersedia koleksi-koleksi yang dimiliki oleh perpustakaan. Pemustaka dapat mengakses koleksi tersebut dengan cara memasukkan judul, pengarang maupun subjek dari suatu koleksi yang dibutuhkan. Sedangkan untuk melakukan peminjaman pemustaka dapat langsung meminjam ke perpustakaan.

d. E-Commerce, E-Commerce merupakan suatu kumpulan yang dinamis antara teknologi, aplikasi dan proses bisnis yang menghubungkan perusahaan, konsumen dan komunitas tertentu melalui transaksi elektronik. Pada perpustakaan website bertujuan untuk menghubungkan antara perpustakaan yaitu melalui pustakawan dan pemustaka yang membutuhkan informasi sehingga terjadinya hubungan yang saling mengutungkan kedua belah pihak.

e. E-Learning, Cisco menjelaskan filosofis e-learning sebagai berikut: Pertama, e-learning merupakan penyampaian informasi, komunikasi, pendidikan, pelatihan secara online. Kedua, e-learning menyediakan seperangkat alat yang dapat memperkaya nilai belajar secara konvensional (model belajar konvensional, kajian terhadap buku teks, CD-ROM, dan pelatihan berbasis komputer) sehingga dapat menjawab tantangan perkembangan globalisasi. Ketiga, e-learning tidak berarti menggantikan model belajar konvensional di dalam kelas, tetapi memperkuat model belajar tersebut melalui pengayaan konten dan pengembangan teknologi pendidikan. Keempat, kapasitas siswa dalam menguasai bahan yang disampaikan lewat e-learning amat bervariasi, tergantung bentuk, isi, dan cara penyampaiannya. Makin baik keselarasan antar konten dan alat penyampai dengan gaya belajar, semakin baik penguasaan siswa yang pada gilirannya akan memberikan hasil yang lebih baik.

f. Komunitas, Sebuah situs website yang dibuat dengan tujuan untuk memungkinkan pengunjung berkomunikasi secara bersamaan. Pengunjung bisa berbagi pengalaman, cerita, ide, dan lainnya, bisa juga mencari dan menambah teman, atau untuk membuat suatu perkumpulan baru.

g. Portal, Portal adalah aplikasi berbasis website yang menyediakan akses suatu titik tunggal dari informasi online terdistribusi, seperti dokumen yang didapat melalui pencarian, kanal berita, dan link ke situs khusus. Untuk memudahkan penggunaannya biasanya disediakan fasilitas pencarian dan pengorganisasian informasi.

h. Personal, Situs personal merupakan situs yang memiliki tujuan untuk mempromosikan atau menginformasikan tentang seseorang. Biasanya berisi tentang biodata, portofolio (kumpulan hasil karya 
yang pernah dibuat), prestasi, atau sebagai diari yang menceritakan kehidupan sehari-hari yang dipublish agar orang lain dapat mengetahui dan mengenal tentangnya.

Blog adalah jenis situs website yang dikembangkan dan dikelola oleh individu dengan menggunakan perangkat lunak (software) online atau platform host yang sangat mudah pengguna, dengan ruang untuk menulis [3]. Blog menampilkan publikasi online instan dan mengajak publik untuk membaca dan memberikan umpan balik sebagai komentar. Dalam definisi yang lebih formal, blog adalah websitesite yang mengandung isi dalam urutan waktu terbalik dan terdiri atas posting-posting. Posting terdahulu akan ditampilkan terlebih dahulu, Baru kemudian posting yang lama [2]. Blog memiliki fitur yang membuat pengguna blog bisa memberikan komentarnya pada tulisan pemilik blog. Selain tulisan dapat pula ditambahkan gambar, video, bahkan bisa pula mengupload file. sehingga pengunjung dapat mengunduh file yang kita masukkan. Berbagai penyedia layanan blog diantaranya adalah blogger.com, Wordpress.com dan multiply.com [4].

Blog dapat dibedakan menjadi 2 yaitu blog engine dan blog service. Blog engine adalah aplikasi berbasis website yang digunakan untuk membuat website blog. Bahasa script yang sering digunakan adalah PHP atau ASP. Namun, blog engine yang dibangun menggunakan PHP masih paling diminati oleh para pengguna. Contoh blog engine yang berbasis PHP adalah Wordpress, Drupal, Geeklog, Joomla, dan Mambo. Keuntungan daripada blog engine adalah pengguna lebih leluasa dalam mengkustom tampilan dan fasilitas dari mesin blog yang dipilih, serta nama domain bebas dipilih selama pengguna membeli domain berbayar, atau mendaftar di hostingan gratis namun menjadi subdomain dari si penyedia domain [8]. Blog service adalah websitesite yang melayani pembuatan blog, layaknya sebuah perusahaan jasa penyedia email. Namun blog service menyediakan script gratis untuk beraktifitas di blog. Contohnya adalah Wordpress, Blogspot, Blogsome, dan Multiply. Kelemahan dari blog service adalah kurangnya kebebasan dalam memodifikasi blog dan nama hanya bisa menjadi subdomain dari penyedia jasa domain [8].

Wordpress.com adalah salah satu di antara sekian banyak layanan blog yang cukup popular. Banyak blogger yang menggunakan Wordpress sebagai pilihan layanan blog yang mereka gunakan, baik secara keseluruhan maupun sebagian("engine" nya saja). Wordpress biasa digunakan oleh blogger yang memang sangat menginginkan kepopuleran. Hal ini karena layanan blog Wordpress ramah komentar. Artinya pembaca bisa menyampaikan komentar mereka dengan sangat mudah pada kotak komentar yang selalu tersedia di bawah setiap artikel [3]. Wordpress dibangun dengan bahasa pemrograman PHP dan database MySQL. PHP dan MySQL, keduanya merupakan perangkat lunak sumber terbuka. Selain sebagai blog, Wordpress juga mulai digunakan sebagai sebuah CMS (Content Management System) karena kemampuannya untuk dimodifikasi dan disesuaikan dengan kebutuhan penggunanya [4].

\section{METODE PENGABDIAN MASYARAKAT}

SMKN 5 kota Mataram membutuhkan tambahan informasi pada website SMKN 5 antara lain beranda, profil, akademik, ekstrakurikuler, sasambo, dan tentang kami. Website pada SMKN 5 kota Mataram menggunakan Wordpress. Wordpress merupakan aplikasi website blog gratis yang mudah dan banyak digunakan oleh banyak orang. Wordpress dibangun dengan bahasa pemrograman PHP dan basis data MySQL. PHP dan MySQL, keduanya merupakan perangkat lunak sumber terbuka. Memposting sesuatu kepada Wordpress memiliki cara yang mudah. Itulah kenapa website SMKN 5 menggunakan Wordpress. Berikut cara melakukan posting pada website SMKN 5 menggunakan Wordpress:

\subsection{Memposting Artikel.}

Cara memposting artikel pada website SMKN 5 menggunakan Wordpress [5]:

a. Dari dashboard klik Posts > Add New.

b. Kemudian Ketik judul Blog.

c. Isikan konten yang sesuai dengan judul Blog.

d. Kemudian masukkan Tags, jika tags sudah ada maka browser akan merespon AUTOCOMPLETION (otomatis melengkapi), jika belum ada maka tags dapat ditulis dengan memberikan tanda koma(,) sebagai tanda pemisah kata kunci tags. Tag bisa diartikan sebagai keyword atau kata-kata penting dalam postingan.

e. Masukkan Category dalam kolom Categories. Jika kategori belum ada silakan klik + Add New Category > ketik nama kategori $>A d d$. Jika sudah ada tinggal mencentang check box di depan kategori yang telah dibuat sebelumnya. Kategori ini merupakan salah satu cara untuk mempermudah pencarian/navigasi $b l o g$.

f. Jika sudah diisi semua, lihat Preview, dan ketika sudah cocok, untuk menampilkannya Klik Publish. 
g. Pengguna juga bisa Save Draft, jika posting belum ingin ditampilkan/proses menulis artikel belum selesai dan akan dilanjutkan dikemudian hari.

h. Silakan Klik Kanan > New Tab pada Visit Site maka hasil postingan dapat dilihat di websitesite.

i. Category dan Tags bersifat opsional, tetapi intinya hanya untuk mempermudah navigasi.

\subsection{Menambahkan Gambar.}

Pada website SMKN 5 dilakukan penambahkan gambar agar mempermudah orang melihatnya. Berikut cara menambahkan gambar [6]:

a. Letakkan kursor pada area posting tepatnya pada bagian yang akan ditempati gambar.

b. Klik tanda Add Media > Add Media > Add an Image.

c. Selanjutnya kita diberi 3 Pilihan yaitu mengirim data dari Komputer lokal (From Computer) atau kedua langsung memberikan alamat Gambar (From URL) dan yang ketiga memilih dari yang sudah diunggah dengan Klik Media Library.

d. Untuk mengambil gambar dari komputer lokal klik Select Files.

e. Pilih File untuk diunggah.

f. Jika gambar sudah muncul, selanjutnya Klik tombol Insert into Post.

g. Gambar selanjutnya sudah ada di Posting.

\subsection{Membuat Page.}

Agar terdapat banyak page untuk memisahkan kategori informasi yang ingin diposting. Berikut cara membuat page [7]:

a. Klik Pages.

b. Klik Add New.

c. Selanjutnya akan muncul tampilan sama persis ketika add post.

d. Masukkan Judul Page.

e. Isikan konten Page.

f. Atur order pada atributes, Order ini akan menentukan urutan dari konten page. Defaultnya berdasarkan alfabet, namun kita bisa mengaturnya berdasarkan pengisian order ini. Isi angka 1 - seterusnya sesuai urutan yang dikehendaki.

g. Jika sudah diisi maka selanjutnya klik Publish.

\section{HASIl DAN PEMBahasan}

SMKN 5 kota Mataram memiliki situs http://smk5mataram.sch.id/. Pada website tersebut membutuhkan tambahan informasi antara lain visi dan misi, struktur organisasi, sarana dan prasarana, kisi-kisi UNBK, sasambo, dan prestasi. Berikut merupakan menu-menu yang ditambahkan.

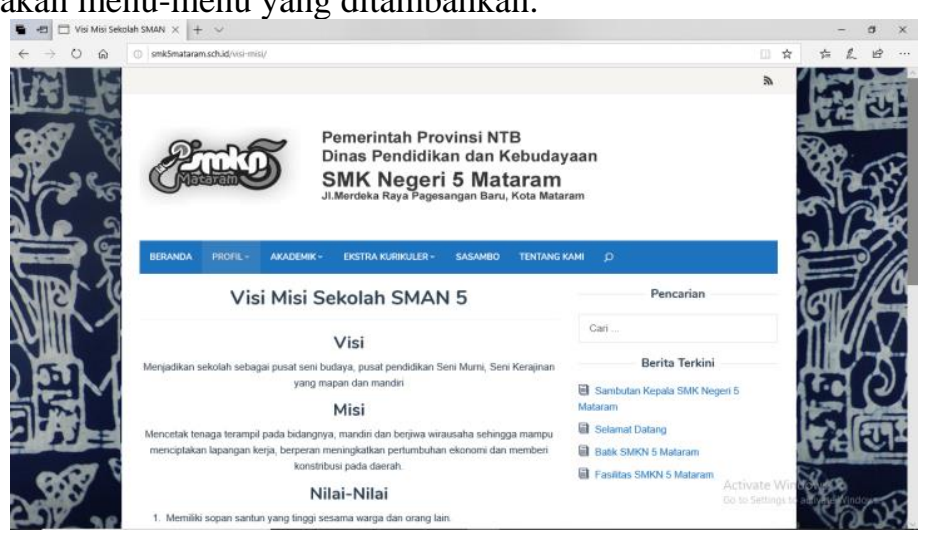

Gambar 1. Tampilan menu visi misi pada SMKN 5 kota Mataram

Pada menu visi dan misi merupakan menu yang menampilkan visi, misi, dan tujuan sekolah. Pada menu tersebut, pengguna dapat melihat visi sekolah, misi sekolah, serta nilai-nilai yang ada pada sekolah SMKN 5 kota Mataram. 
Isi dari menu tersebut terdapat 3 poin antara lain visi, misi, dan nilai-nilai. Pada poin visi isinya adalah "Menjadikan sekolah sebagai pusat seni budaya, pusat pendidikan Seni Murni, Seni Kerajinan yang mapan dan mandiri". Dan untuk misi berisi "Mencetak tenaga terampil pada bidangnya, mandiri dan berjiwa wirausaha sehingga mampu menciptakan lapangan kerja, berperan meningkatkan pertumbuhan ekonomi dan memberi kontribusi pada daerah.”.

Pada poin nilai-nilai memiliki banyak poin mengenai nilai-nilai sekolah. Yaitu :

a. Memiliki sopan santun yang tinggi sesama warga dan orang lain.

b. Transparan, adanya keterbukaan dalam mengambil keputusan dan hubungan antar sekolah.

c. Transparan, adanya keterbukaan dalam mengambil keputusan dan hubungan antar sekolah.

d. Adaptif, Peka terhadap perubahan IPTEK dan berusaha untuk dapat mengimbangi perubahan IPTEK dengan tetap berpegang teguh pada nilai-nilai luhur bangsa.

e. Kebersamaan dan keteladanan, Dengan motto "together must be success" dan "together in smkn5 mataram" SMK Negeri 5 Mataram berupaya memupuk kerja sama yang baik dalam mencapai tujuan dan memberikan keteladanan dalam menjalankan misi kependidikan. Baik secara internal dan eksternal.

f. Inovatif dan Kreatif, Terbuka terhadap inovasi baru, bertindak kreatif terhadap ide-ide baru sehingga dapat mengembangkannya demi kemajuan bersama.

g. Religius, Menjunjung tinggi nilai-nilai keagamaan dan mencerminkannya dalam kehidupan sehari-hari.

h. Sopan, Santun, Salam dan Senyum, Bersikap ramah, sopan dan santun terhadap orang lain dengan menyapa dan menyampaikan salam sambil tersenyum.

i. Pelayanan Prima, Mengutamakan pelayanan yang berkualitas dan profesional, demi kepuasan pelanggan.

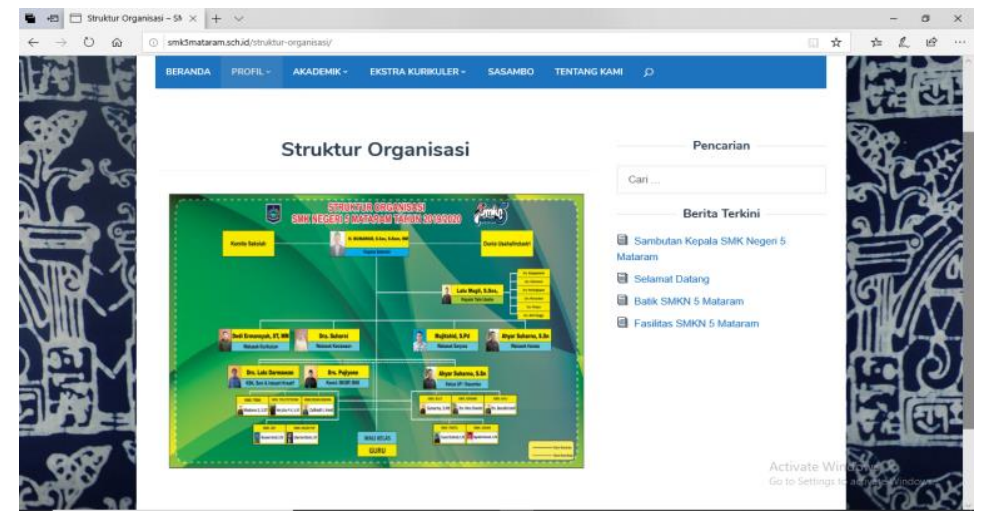

Gambar 2. Tampilan menu struktur organisasi pada SMKN 5 kota Mataram

Menu struktur organisasi merupakan menu yang menampilkan struktur organisasi sekolah. Pada menu tersebut hanya terdapat gambar struktur organisasi sekolah. Struktur tersebut meliputi komite sekolah, kepala sekolah, hingga wali kelas dan guru.

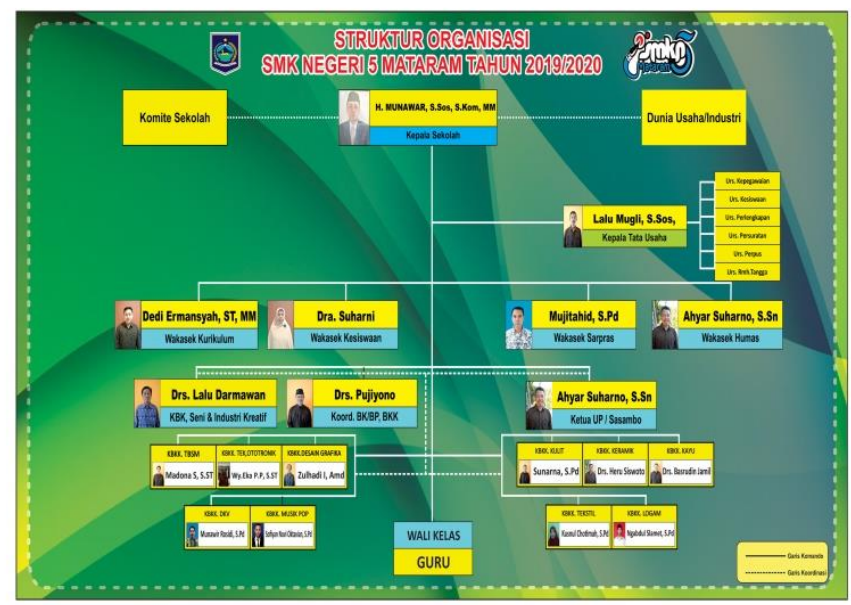

Gambar 3. Struktur Organisasi SMKN 5 kota mataram 
Pada Gambar 3 merupakan struktur organisasi SMKN 5 kota Mataram. Struktur tersebut meliputi komite sekolah, kepala sekolah, hingga wali kelas dan guru. Pada gambar struktur organisasi SMKN 5 kota Mataram menampilkan wajah dari orang tersebut agar memudahkan pengguna website mengetahui identitas salah satu anggota dari struktur organisasi SMKN 5.

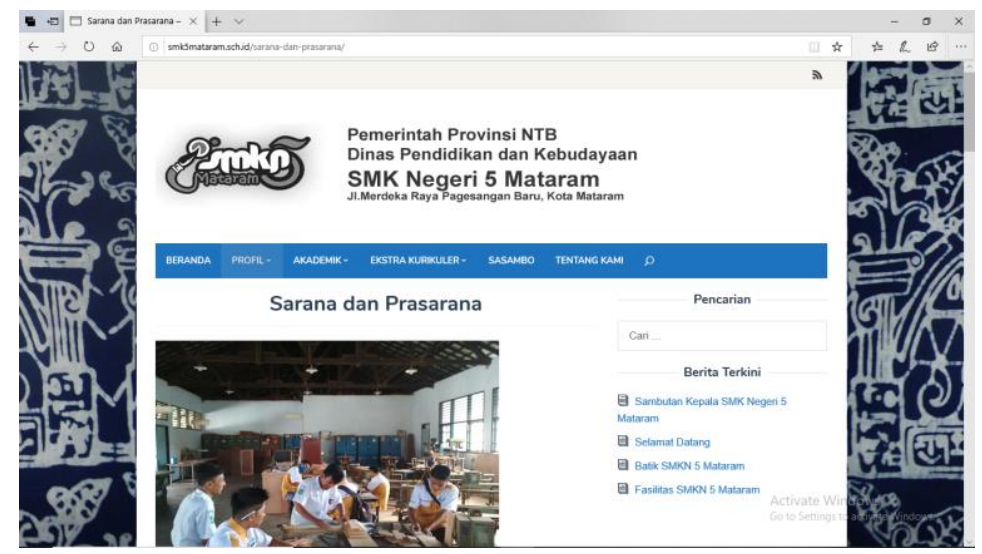

Gambar 4. Tampilan menu sarana dan prasarana pada SMKN 5 kota Mataram

Menu sarana dan prasarana adalah menu yang menampilkan fasilitas-fasilitas pada sekolah SMKN 5 kota Mataram. Pada menu tersebut menampilkan gambar-gambar fasilitas serta kegiatan di sekolah SMKN 5 kota Mataram. Gambar-gambar tersebut meliputi ruang kelas, bengkel, dan lain-lain.

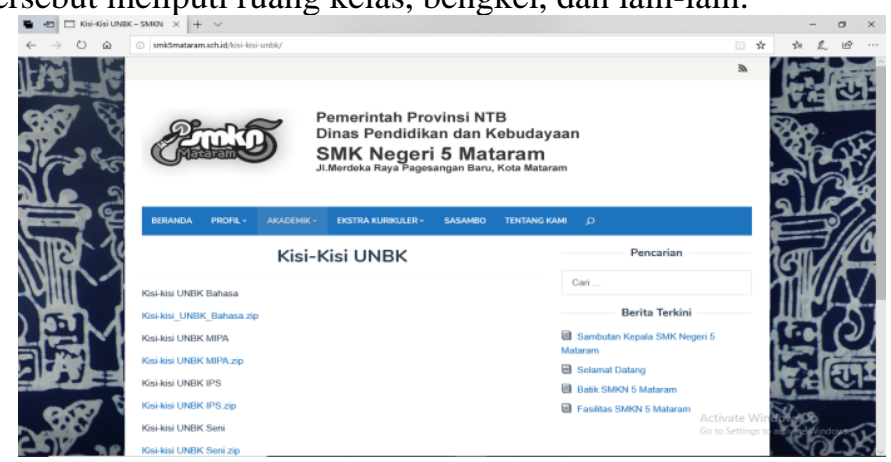

Gambar 5. Tampilan menu kisi-kisi UNBK pada SMKN 5 kota Mataram

Menu kisi-kisi UNBK merupakan menu yang terdapat dibagian akademik yang menampilkan kisi-kisi yang digunakan untuk Ujian Nasional Berbasis Komputer (UNBK). Pada menu tersebut berisi link untuk mengunduh file kisi-kisi UNBK. Sehingga dapat memudahkan user untuk mendapatkan kisi-kisi.

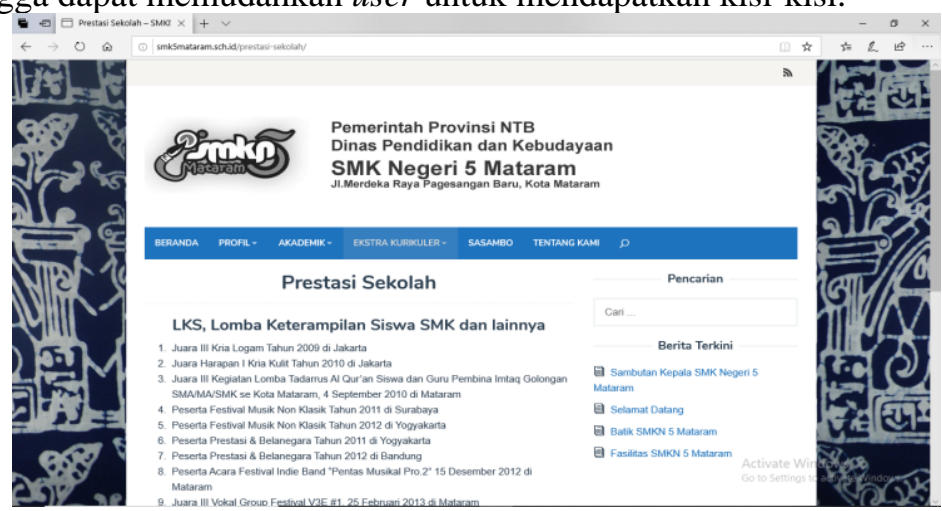

Gambar 6. Tampilan menu prestasi sekolah pada SMKN 5 kota Mataram

Pada menu prestasi sekolah merupakan menu yang berada di bagian Ekstrakurikuler. Menu tersebut menampilkan prestasi sekolah pada Lomba Keterampilan Siswa (LKS), pameran, serta perserta didik.

Prestasi tersebut antara lain :

a. Lomba Keterampilan Siswa (LKS) 
Berikut merupakan kejuaraan LKS yang didapatkan SMKN 5 :

1. Juara III Kria Logam Tahun 2009 di Jakarta.

2. Juara Harapan I Kria Kulit Tahun 2010 di Jakarta.

3. Juara III Kegiatan Lomba Tadarrus Al Qur'an Siswa dan Guru Pembina Imtaq Golongan SMA/MA/SMK se Kota Mataram, 4 September 2010 di Mataram.

4. Peserta Festival Musik Non Klasik Tahun 2011 di Surabaya.

5. Peserta Festival Musik Non Klasik Tahun 2012 di Yogyakarta.

6. Peserta Prestasi \& Belanegara Tahun 2011 di Yogyakarta.

7. Peserta Prestasi \& Belanegara Tahun 2012 di Bandung.

8. Peserta Acara Festival Indie Band "Pentas Musikal Pro.2" 15 Desember 2012 di Mataram.

9. Juara III Vokal Group Festival V3E \#1, 25 Februari 2013 di Mataram.

10. Juara Harapan III Kegiatan Lomba Usaha Kesehatan Sekolah (UKS) Tingkat Kota Mataram 3 Juli 2013.

11. Juara 2 lomba kreasi jingle Promosi Perpustakaan Nasional RI melalui Roadshow 25 September 2013 di Jakarta.

12. Peserta Choir Competition For Senior High School 30 Nopember 2013 di Provinsi Nuasa Tenggara Barat.

13. Peserta Pegelaran Seni Pelajar 21 Februari 2014 di Taman Budaya Provinsi Nusa Tenggara Barat.

b. Pameran

Berikut merupakan pameran yang diselenggarakan di SMKN 5 :

1. Ekspos SMK Negeri 5 Mataram I Tahun 2007 di Mataram.

2. Ekspos SMK Negeri 5 Mataram II Tahun 2010 di Mataram.

3. Pameran Gebyar SMK se-Kota Mataram Tahun 2012.

4. Pameran Produk Kreatif Indonesia (PPKI) di Jakarta.

5. Pameran Nasional Hari Nusantara Tahun 2012 di Lombok Timur, NTB.

c. Peserta didik

Berikut merupakan data prestasi peserta didik di SMKN 5 :

1. Juara I LKS Bidang Lomba Textile Craft (Kria Tekstil) Tingkat Provinsi Nusa Tenggara Barat an. Lalu Iwan Sanusi 30 Agustus 2013.

2. Juara I LKS.

Berdasarkan wawancara terhadap guru dan siswa SMKN 5 kota Mataram bahwa hasil website SMKN 5 kota Mataram yang dikerjakan pada kegiatan pengabdian ini sangat bermanfaat dan informatif. Informasi sekolah yang ingin disampaikan sudah sesuai dan sudah diposting. Tidak hanya informasi mengenai sekolah, Namun juga menampilkan hasil karya siswa dan siswi SMKN 5 kota Mataram yaitu batik sasambo yang dapat menjadi daya tarik sekolah.

\section{KESIMPULAN DAN SARAN}

Berdasarkan hasil dan pembahasan atas pelaksanaan kegiatan pengabdian di SMKN 5 Kota Mataram dapat diambil beberapa kesimpulan yaitu :

1. Website pada SMKN 5 kota Mataram menggunakan Wordpress. Informasi yang diposting pada website tersebut dalam bentuk teks dan gambar. Page yang ditambah pada website SMKN 5 adalah visi dan misi, struktur organisasi, sarana dan prasarana, kisi-kisi UNBK, sasambo, dan prestasi.

2. Informasi yang ingin disampaikan kepada publik sudah diposting kepada website SMKN 5 sehingga website tersebut dapat digunakan dan dilihat oleh siswa, guru, serta orang luar yang mengakses website ini.

Adapun saran yang dapat diberikan dalam kegiatan pengbadian ini adalah website SMKN 5 kota Mataram belum dilengkapi dengan sistem security yang kuat sehingga masih rentan dengan gangguan dari luar. 


\section{UCAPAN TERIMA KASIH}

Ucapan terima kasih kepada kepala sekolah yang telah memberikan kesempatan melakukan kegiatan pengandian masyarat. Para guru dan karyawan yang memberikan data dan informasi untuk diposting ke website. Serta kepada teman-teman yang membantu penulis dalam melaksanakan pengabdian ini.

\section{DAFTAR PUSTAKa}

[1] H. Hartono. Pengertian Website dan Fungsinya . Teknik Informatika. Tangerang. 2014

[2] A. Fitriani., A. Zubaidi., \& A.H. Jatmika. Sistem Informasi Kegiatan Program Studi Teknik Informtaika Universitas Mataram. Jurnal Teknologi Informasi, Komputer, Dan Aplikasinya (JTIKA ). 2020

[3] Mustianti , I.B.K. Widiartha,., \& M.A. Albar. Sistem Informasi Tugas Akhir Program Studi Informatika. Jurnal Teknologi Informasi, Komputer, Dan Aplikasinya (JTIKA ). 2020

[4] J.J.C.Y Prawira dan T.I Wardani. Aplikasi CMS Wordpress Untuk Pembuatan Websitesite Sebagai Media Promosi Di Wisata Keramik Dinoyo Kota Malang. Jurnal Aplikasi Bisnis, 3(2). 2018

[5] H. Destiwanto. Panduan Ngeblog Wordpress. Universitas Sebelas Maret. Surakarta. 2011

[6] Ainurrofik. Panduan Dasar Membuat Websitesite Menggunakan Wordpress Versi 3.x. Websitehostmu.com. 2014

[7] Hartoto. Panduan Dasar Membuat Websitesite Menggunakan Wordpress Versi 3.x. Websitehostmu.com. 2014

[8] O. Suryana dan M. Studio . Membangun Blog Wordpress. Elex Media Komputindo. 2013

[9] Y. Kurniawan. Ngeblog dengan Wordpress itu Gampang. Elex Media Komputindo. 2013

[10] D. M Harja, S. E. Anjarwani, \& A. Zubaidi.. Sistem Informasi Koperasi Pegawai Negeri (KPN) Universitas Mataram Berbasis Website. Journal of Computer Science and Informatics Engineering (J-Cosine), 2(2). 2018 